Check for updates

The BMJ

Cite this as: BMJ 2020;371:m4826 http://dx.doi.org/10.1136/bmj.m4826 Published: 11 December 2020

\title{
Covid-19: Pfizer vaccine efficacy was 52\% after first dose and $95 \%$ after second dose, paper shows
}

\section{Elisabeth Mahase}

The Pfizer and BioNTech covid-19 vaccine may provide some early protection, starting 12 days after the first dose, the peer reviewed results of a phase III trial have found.

The study, published in the New England Journal of Medicine, ${ }^{1}$ found that vaccine efficacy between the first and second doses was 52\% (95\% credible interval $29.5 \%$ to $68.4 \%$ ), with 39 cases of covid-19 in the vaccine group and 82 cases in the placebo group.

Seven or more days after the second dose, vaccine efficacy then rose to $95 \%$ (90.3\% to $97.6 \%$ ), with eight covid-19 cases reported in the vaccine group and 162 cases in the placebo group.

The vaccine has so far been approved in Canada and in the UK, where it is already being rolled out to people over 80 and healthcare workers. In the US the Food and Drug Administration's independent panel has voted in favour of emergency use authorisation for the vaccine, and the agency is expected to approve it within days. ${ }^{2}$

\section{Participants}

From July to November 2020, 43448 adults were randomly assigned at 152 sites worldwide (including in Argentina, Brazil, Germany, South Africa, Turkey, and the US) as part of the phase II/III trial of the $\mathrm{BNT} 162 \mathrm{~b} 2$ vaccine. A total of 21720 people received two doses 21 days apart, and 21728 received a placebo.

The paper reported that, seven days after the second dose, vaccine efficacy ranged from $89 \%$ to $100 \%$ across subgroups defined by age, sex, race, ethnicity, baseline body mass index, and the presence of coexisting conditions.

The study found 10 severe covid-19 cases after the first dose, nine of which were in the placebo group. After the second dose it showed one case in the vaccine group and four in the placebo group. ${ }^{3}$

As of 9 October, 37706 participants had a median of at least two months' safety data available after a second dose. Among these participants $49 \%$ were female, $83 \%$ were white, $9 \%$ were black or African-American, 28\% were Hispanic or Latinx, 35\% had a body mass index of at least 30 , and $21 \%$ had at least one pre-existing condition. The median age was 52 , and $42 \%$ of participants were aged over 55 .

\section{Adverse events}

In terms of safety, more people in the covid-19 vaccine group reported any adverse event $(27 \%$, compared with $12 \%$ taking a placebo) or a related adverse event $(21 \% v 5 \%)$. The researchers said that this was mainly due to transient reactogenicity events, such as injection site pain.
Few participants in either group had severe or serious adverse events. Among the BNT162 b2 recipients four related serious adverse events were reported and two recipients died (one from arteriosclerosis and one from cardiac arrest), as did four placebo recipients (two from unknown causes, one from haemorrhagic stroke, and one from myocardial infarction).

However, none of the deaths was considered by the investigators to be related to the vaccine or placebo, and no covid-19 associated deaths were observed.

The researchers wrote, “The safety profile of BNT162b2 was characterised by short term, mild-to-moderate pain at the injection site, fatigue, and headache. The incidence of serious adverse events was low and was similar in the vaccine and placebo groups.”

Polack FP, Thomas SJ, Kitchin N, et al. Safety and efficacy of the BNT162b2 mRNA covid-19 vaccine. NEngl/JMed2020. doi: 10.1056/NEJMoa2034577. https://www.nejm.org/doi/full/10.1056/NEJMoa2034577?query=RP.

2 Tanne JH. Covid-19: FDA panel votes to approve Pfizer BioNTech vaccine BMJ 2020;371:m4799doi: 10.1136/bmj.m4799.

3 Polack FP, Thomas SJ, Kitchin N, et al. Supplementary appendix to "Safety and efficacy of the BNT162b2 mRNA covid-19 vaccine." N EnglJ Med 2020. https://www.nejm.org/doi/suppl/10.1056/NEJMoa2034577/suppL_file/nejmoa2034577_appendix.pdf.

This article is made freely available for use in accordance with BMJ's website terms and conditions for the duration of the covid-19 pandemic or until otherwise determined by BMJ. You may use, download and print the article for any lawful, non-commercial purpose (including text and data mining) provided that all copyright notices and trade marks are retained. 